\title{
An Econometric Framework for Evaluating the Efficiency of a Market for Transmission Congestion Contracts
}

\author{
Timothy D. Mount \\ Professor at the Charles H. Dyson School \\ of Applied Economics and Management \\ Cornell University \\ tdm2@cornell.edu \\ Jaeuk Ju \\ Research Fellow at the \\ Korea Information Society Development Institute \\ jujaeuk@kisdi.re.kr
}

\begin{abstract}
The goals of this paper are to 1) simulate the ex-ante riskiness of purchasing a TCC, and 2) evaluate the efficiency of the TCC market in New York State to determine if there is evidence of under-pricing. Three VAR models are estimated using only market data available before the auction. This model is then used to simulate the daily payouts of a TCC for the following summer. A Monte Carlo procedure simulates the daily summer temperatures, the levels of quantity demanded and prices over the summer months. The main empirical result is that the market price paid for the most important TCC, in terms of volume, (the Hudson Valley to New York City) is higher than the mean of the simulated payouts even though the actual payout was higher than the market price. The market prices for the other two TCCs are lower than the means of the simulated payouts, and as a result, there is no consistent evidence of under-pricing in this analysis of the market for six-month TCCs in the summer of 2006.
\end{abstract}

Keywords: Electricity prices; Econometric models; TCC; Financial risk 


\section{Introduction}

The electricity market in New York State was restructured in November, 1999, and by 2006, the number of nodes on the network had increased to more than 400. The electricity price at each node is called the nodal price and these prices are determined by the system operator in an auction based on the offers submitted by different generators. Nodal prices are highly volatile and price spikes can occur in load pockets ${ }^{1}$, like New York City, when the demand for electricity is high and transmission lines are congested. The congestion cost can be determined from the nodal price difference between two different nodes after accounting for losses. Since nodal prices and congestion costs are intrinsically uncertain, different kinds of financial instruments, such as Transmission Congestion Contracts (TCC), have been developed to hedge against the risk of price differences between areas. The theory of Financial Transmission Rights (FTR) has been discussed by Hogan (1992), Hogan (1997), Joskow (2000), Joskow (2005), Cai (2005) and Zhang (2009). Since the transmission corridor from the Hudson Valley to New York City is the most important transmission bottleneck in New York State, the efficiency of the market for this TCC has been of particular interest to policy makers. In the Transmission Congestion Contract Manual published by the New York Independent System Operator (NYISO) (NYISO, 2007), a TCC is defined as follows: ${ }^{2}$

A TCC represents the right to collect, or the obligation to pay, the Day-Ahead Market (DAM) Congestion Rents associated with 1-Megawatt (MW) of transmission between a specified Point of Injection (POI) and specified Point of Withdrawal (POW). The DAM Congestion Rents are determined by the difference in the Congestion Component of the DAM, Locational Based Marginal Price (LBMP) at the POW of the TCC and the Congestion Component of the DAM LBMP at the POI of the TCC, for each hour of the Effective Period.

The objectives of this paper are to develop an analytical framework for 1) simulating the ex-ante riskiness of purchasing a TCC, and 2) evaluating

\footnotetext{
${ }^{1}$ the area in which the electricity demand is higher than surrounding areas

${ }^{2}$ p.2-1, Transmission Congestion Contract Manual
} 
the efficiency of the TCC market in New York State. This is accomplished by estimating an econometric model to simulate the stochastic behavior of nodal prices and derive the stochastic characteristics of the corresponding congestion costs for a chosen TCC and, in particular, the TCC for the link from the Hudson Valley to New York City. Through this process, simulated price differences are used as the basis for measuring the financial riskiness of congestion costs. The model predicts the prices in four different zones, A (West), G (the Hudson Valley), J (New York City) and K (Long Island). The basic specification for the model is that uncertainty about future temperatures is the main source of financial risk because it leads to uncertainty about future levels of quantity demand, and this, in turn, leads to uncertainty about future prices. In the econometric model, each price of electricity in a zone is a function of the corresponding level of quantity demand, the price of natural gas and a set of seasonal and daily variables, the quantity demanded in a zone is a function of the corresponding temperature and a set of seasonal and daily variables, and the temperature in a zone is a function of a set of seasonal variables.

Three multivariate time-series models (Vector Auto-Regressive (VAR)) were estimated using daily data from 2002 to 2005 for 1) the residuals from the model for daily temperature in different locations conditional on seasonal cycles, 2) the residuals from the model for the average daily quantities demanded in different zones conditional on Heating Degree Days (HDD), Cooling Degree Days (CDD), seasonal cycles and dummy variables for days of the week, and 3) the residuals from the model for the prices of electricity in different zones conditional on quantity demanded, a polynomial lag of past prices of natural gas at Henry Hub, seasonal cycles and dummy variables for days of the week. A separate Auto-Regressive Integrated Moving Average model (ARIMA) for the price of natural gas at Henry Hub was also estimated. The structure of this model captures relationships across locations while maintaining a recursive structure of the overall model. In other words, temperature is treated as an exogenous variable in a quantity demanded equation, and quantity demanded and the price of natural gas are treated as exogenous variables in a price equation. Although the assumption of exogeneity of quantity demanded can be challenged, no solid evidence of simultaneity between price and quantity demanded was found for these data. This would probably not be true using more current data because quantity demanded response has become more important and more customers are now directly exposed to real-time prices. In addition, the use of daily data was 
considered to be a sensible level of aggregation because TCC payments cover every hour over a contract period, and using an hourly model would involve much greater complexity to capture the seasonal changes of daily quantity demanded profiles. Even with the simplifications of using a recursive structure and daily data, the estimation still posed computational challenges for the statistical package (SAS) such as eigenvalue computation failure, and each set of equations had to be estimated in two stages. However, the statistical properties of the final model are satisfactory and it explains over $90 \%$ of the variability for every dependent variable, and most importantly, it replicates price behavior well.

The estimated models were then used to simulate daily price differences between zones A-G, A-J, G-J and J-K for the summer of 2006. The sum of these price differences from May to October determines the earnings of a six-month strip for the corresponding TCC. Since the models were estimated using only information that was available before the auction to sell the TCCs, it is appropriate to use these models to simulate the ex-ante financial risk of purchasing a TCC in the auction. Ten thousand different realizations of the daily temperatures in different locations and the price of natural gas are simulated for May to October 2006 to represent a random sample of 10,000 summers. Each realization of the daily price of natural gas is paired with one realization of the three daily temperatures to simulate 10,000 daily quantities demanded and the corresponding daily prices of electricity in the four zones. These prices are then used to compute the daily price differences. The 10,000 payouts from holding a TCC for May to October 2006 are computed by scaling and aggregating the daily price differences. Finally, the average simulated TCC payout from holding a TCC is compared with the actual market clearing price for each TCC in the auction. If the auction price is found to be significantly lower than the average value, this would indicate evidence of underpricing. The empirical analysis shows that there is no consistent evidence of underpricing, and in particular, the auction price is higher than the average simulated price for the highest volume TCC from the the Hudson Valley to New York City (zones G-J).

Many trials to model electricity prices or relavant transaction costs with other variables including seasonality are found in various previous literatures. Park et al. (2006) examined 11 U.S. electricity spot market prices using time series analysis. Then, Park et al. (2007) also developed bivariate three-regime threshold vector error correction models to examine seasonality in transaction cost and supply and demand between markets. They found 
that in the natural gas sector, dynamic threshold effects vary depending on season, geographical location and whether the market is an excess producing or consuming market. Mjelde and Bessler (2009) studied dynamic price information flows among U.S. electricity wholesale spot prices and the prices of their major sources. Market efficiency has been studied in many researches including Fama (1998).

\section{The Spatial Structure of Nodal Prices in the New York Elec- tricity Market}

The electricity market in New York State has 11 zones: West (A), Genesee (B), Central (C), North (D), Mohawk Valley (E), Capital (F), Hudson Valley (G), Millwood (H), Dunwoodie (I), New York City (J), and Long Island $(\mathrm{K})$. Real-time nodal price data are available on the NYISO website (www.nyiso.com), and the total number of nodes in New York State, including interstate transmission nodes to adjoining systems has increased consistently from 359 in 1999 to 453 in 2007. In Table B.1 the number of nodes by zone in New York State from 1999 to 2007 is shown. ${ }^{3}$ In general, nodal prices are lowest in the west of the state and get higher moving east and south, with the highest prices occurring in zones $\mathrm{J}$ and $\mathrm{K} .{ }^{4}$

In Figure 1 the annual mean hourly real-time prices for each node in 2001 and 2005 are shown. The 11 zones are listed in alphabetical order and the order of nodes is the same for each year using the ranked mean price within each zone in 2007. The plots also show the averages for the highest 10 percent of prices (average peak prices) and the averages for the lowest 10 percent of prices (average base prices) using the same nodal ordering as the mean prices. By comparing the plots for 2001 and 2005 in Figure 1 it is shown that the spatial differences among the average peak prices were substantially larger in 2005 than in 2001, implying that congestion increased over time. In addition, the differences among average peak price within zone $\mathrm{J}$ were significantly higher in 2005 than they were in 2001. In 2001, the biggest price differences were between zone A and zones $\mathrm{J}$ and $\mathrm{K}$, but in 2005, the biggest differences are within zone $\mathrm{J}$ even though there was no significant increase in the electricity quantity demanded in zone J (see Figure 3). A

\footnotetext{
${ }^{36} \mathrm{U}$ ' is the group of nodes with an unidentified zone.

${ }^{4}$ These high prices are caused by congestion on the transmission network into New York City and Long Island.
} 

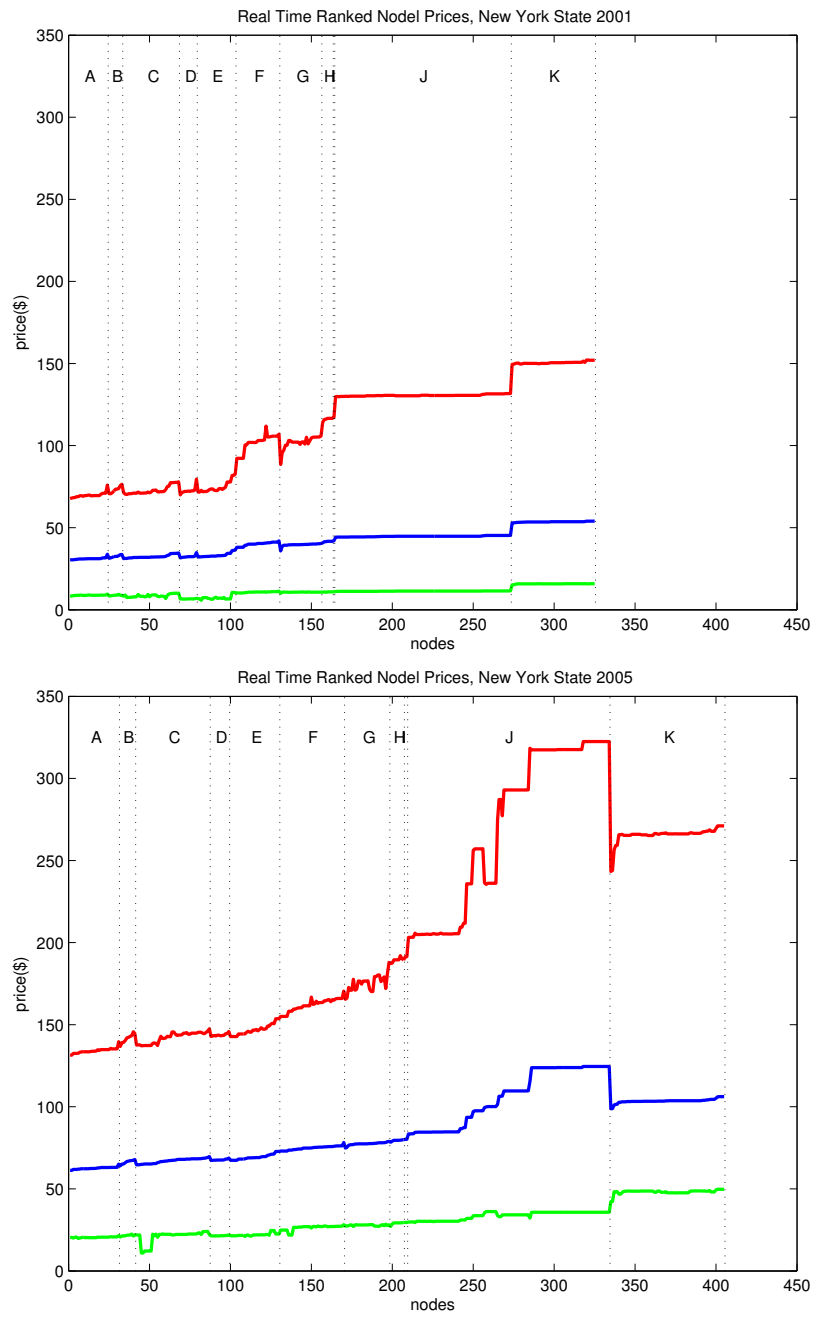

Figure 1: Ranked Nodal Prices, New York State, 2001, 2005 
possible explanation for this change is that modifications were made in how the nodal prices were computed by the NYISO. Since the spatial structure of the market is very complicated at the nodal, the analysis that follows is based on the average prices in zones A, G, J and K. These zones were chosen to capture the major sources of congestion on the network, and in particular, the congestion between the Hudson Valley (zone G) and New York City (zone $\mathrm{J})$.

\section{Econometric Models for Temperature, Electricity Quantity De- manded, and Electricity Price}

Since congestion costs can be calculated from the differences in electricity prices between zones, these costs can be derived directly from models of the prices of electricity in the four chosen zones if the spatial relationships among these prices are represented effectively. For this reason, three Vector AutoRegressive models (VAR) based on the residuals from the regression models were chosen. The dependent variable for each zone is the quantity-weighted average daily price in the day-ahead market. Even though this choice avoids the greater complexity of fitting an hourly model, it is still appropriate for the analysis because a TCC pays a fixed quantity times the price difference for every hour of a contract. In addition, estimating this simple model structure still presented computational challenges for the statistical package (SAS). Each price is expressed as a function of the quantity demanded for electricity, a distributed lag of the price of natural gas and seasonal and weekly effects. The residuals for each equation are VAR functions of the lagged residuals in all four price equations. The main source of uncertainty about future price differences is assumed to come from uncertainty about future levels of quantity demanded caused by uncertainty about future temperatures, and VAR models of temperature and quantity demanded are estimated to capture these sources of uncertainty.

\subsection{The model for temperature}

Temperature is one of the most important factors determining the quantity demanded for electricity. The two-step model uses the daily temperature data collected for Buffalo for zones A-F, Stewart Field for zones G-I, and LaGuardia Airport for zones J and K, and in Figure 2 the plots of these daily temperatures from 2002 to 2006 are shown. The dominant seasonal pattern of temperature was captured by a one-year cycle and a half-year cycle using 

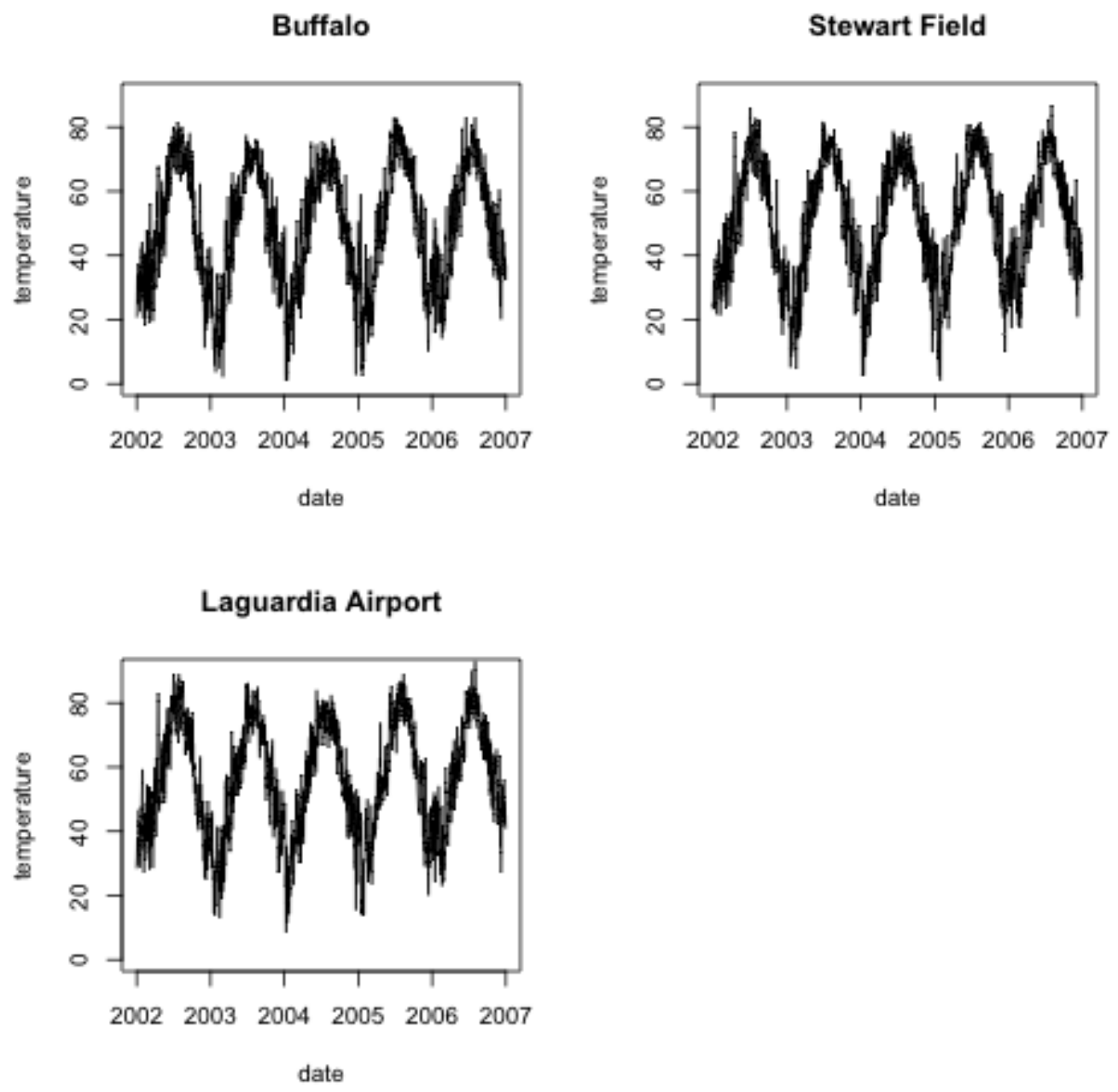

Figure 2: Temperature 
sine and cosine functions in the first step of the estimation. In the second step, a second-order $\operatorname{VAR}(2)$ model was estimated for the computed residuals to capture the spatial relationships. The order of the VAR model was selected using the Schwarz Bayesian Criterion $(\mathrm{SBC})^{5}$.

Since this is the first one of the three models presented in this section, it is used to illustrate the general structure of the two-step estimation procedure. The temperature model has the following algebraic form:

Temperature Model.

the first step:

$$
\mathbf{x}_{t}=\mathbf{B} \cdot\left[\begin{array}{c}
1 \\
c h_{t} \\
c 1_{t} \\
s 1_{t}
\end{array}\right]+\mathbf{u}_{t}
$$

the second step:

$$
\Phi(L) \mathbf{u}_{t}=\epsilon_{t}
$$

$\mathbf{x}_{t}$ is a vector for the temperatures at Buffalo, Stewart Field and LaGuardia Airport. $\mathbf{B}$ is a $3 \times 4$ matrix for coefficients. $c h_{t}$ is a cosine variable with a period of six months, $c 1_{t}$ is a cosine variable with a period of one year and $s 1_{t}$ is a sine variable with a period of one year. A sine variable with period of six months was excluded because the estimated coefficients were not statistically significant. $\mathbf{u}_{t}$ is the residual, which is computed from the deseasonalized temperature variables. $\Phi(L) \mathbf{u}_{t}=\epsilon_{t}$ is the $\operatorname{VAR}(2)$ model for the residual $\mathbf{u}_{t}$. Therefore, $\mathbf{u}_{t}$ is equivalent to a vector for temperature with seasonal patterns removed in 3 zones and $\epsilon_{t}$ is a white noise vector. $L$ is the lag operator. In Table B.2 the parameter estimates of first-step model of temperature are shown and in Table B.3 the estimated coefficients of the $\operatorname{VAR}(2)$ model are shown. The numbers in parentheses are t ratios showing that most of the coefficients are estimated accurately, and in general, the model explains the data well. In the second stage, 8 coefficients out of 9 are found to be significant for lag 1, and 7 are significant coefficients for lag 2 .

\subsection{The model for electricity quantity demanded}

The model for electricity quantity demanded assumes implicitly that the price of electricity at a specific location is influenced by the aggregate quan-

\footnotetext{
${ }^{5}$ The SBC are 7.649001 for $\operatorname{VAR}(1), 7.560281$ for $\operatorname{VAR}(2)$ and 7.572565 for $\operatorname{VAR}(3)$.
} 

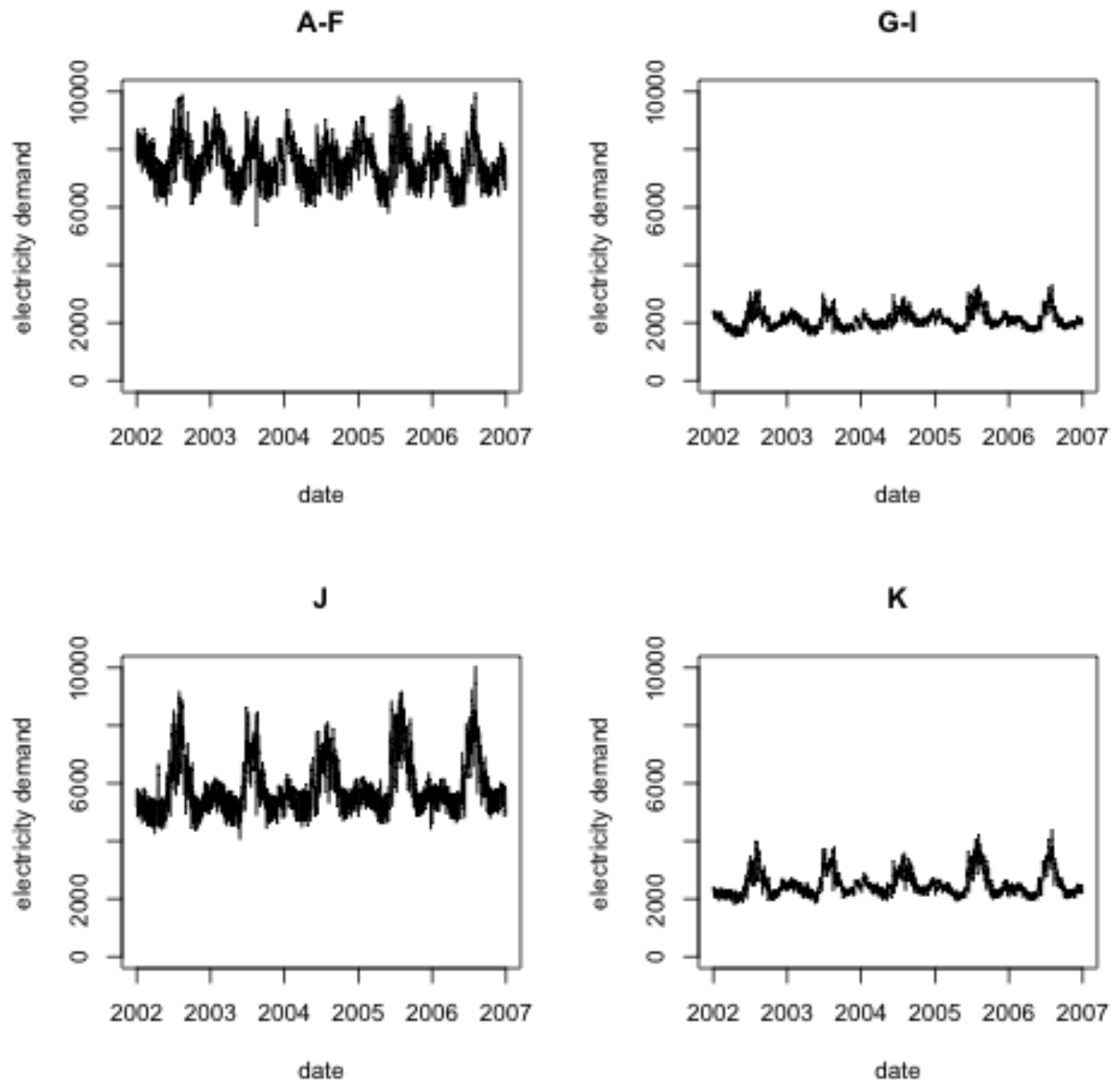

Figure 3: Electricity Consumption 
tity demanded in the surrounding region, represented by the aggregate quantity demanded in specified zones. Figure 3 is the plot of daily quantities demanded of electricity in four regions in New York State. These are zones A-F, zones G-I, zone J and zone K. The last two zones represent the high demand in the major urban areas. The daily quantity demanded for electricity has a seasonal pattern that is different from temperature because the quantity demanded for electricity increases in the summer for cooling and also in the winter for heating. One reason for the relatively low winter peak is that natural gas is the main fuel used for heating. Quantity demanded also has weekly patterns reflecting work days and weekends. Since quantity demanded has a bimodal pattern, temperature is incorporated into the model as Heating Degree Days (HDD) and Cooling Degree Days (CDD) using 65 degrees as the base. Linear, quadratic and lagged values of HDD and CDD are included in the model. In addition, dummy variables for days of the week are included as well as interactions between the weekly effects and CDD (to capture the effects of the quantity demanded needed for air conditioning).

For $i \in\{1,2,3,4\}$, an equation for electricity quantity demanded in a region can be written as follows:

Quantity Demanded Model.

$$
\begin{aligned}
d_{i t}= & \beta_{i 0}+\beta_{i 1} t_{t}+\beta_{i 2} \text { ch }_{t}+\beta_{i 3} s h_{t}+\beta_{i 4} c 1_{t}+\beta_{i 5} s 1_{t}+\beta_{i 6} c 2_{t}+\beta_{i 7} s 2_{t}+ \\
& \gamma_{i 1} \text { sunday }_{t}+\gamma_{i 2} \text { monday }_{t}+\gamma_{i 3} \text { tuesday }_{t}+ \\
& \gamma_{i 4} \text { wednesday }_{t}+\gamma_{i 5} \text { thursday }_{t}+\gamma_{i 6} \text { friday }_{t}+\gamma_{i 7} \text { holiday }_{t} \\
& \delta_{i 1} H D D_{i t}+\delta_{i 2} H D D_{i t}^{2}+\delta_{i 3} C D D_{i t}+\delta_{i 4} C D D_{i t}^{2}+ \\
& \delta_{i 5} H D D_{i t-1}+\delta_{i 6} C D D_{i t-1}+ \\
& \zeta_{i 1} C D D_{i t} \times \text { sunday }_{t}+\zeta_{i 2} C D D_{i t} \times \text { monday }_{t}+ \\
& \zeta_{i 3} C D D_{i t} \times \text { tuesday }_{t}+\zeta_{i 4} C D D_{i t} \times \text { wednesday }_{t}+ \\
& \zeta_{i 5} C D D_{i t} \times \text { thursday }_{t}+\zeta_{i 6} C D D_{i t} \times \text { friday }_{t}+u_{i t} \\
& \Phi(L) \mathbf{u}_{t}=\epsilon_{t}
\end{aligned}
$$

$i=1$ : zones A-F

$i=2$ : zones G-I

$i=3$ : zone $\mathrm{J}$

$i=4$ : zone $\mathrm{K}$

$d_{i t}$ : log of electricity quantity demanded

$t_{t}$ : time trend 
$c h_{t}, s h_{t}, c 1_{t}, s 1_{t}, c 2_{t}, s 2_{t}$ : seasonal variables (cosine and sine curves with half year, 1 year and 2 years periods)

sunday $_{t}$, monday $_{t}$, tuesday $_{t}$, wednesday, thursday, friday $_{t}$ : weekly dummy variables

holiday $y_{t}$ dummy variable for a holiday

$H D D_{i t}, C D D_{i t}$ : heating degree days and cooling degree days

Table B.4 and Table B.5 show the parameter estimates for electricity quantity demanded in the four regions. Most of the coefficients, including the interaction terms, are statistically significant at the $5 \%$ level in all four regions and the model fits the data well. For all four regions, trend variables are significant at the $5 \%$ level and most seasonal variables are also significant at the $5 \%$ level but not those with a period of half a year. All of the weekly dummy variables are highly significant for all areas at the $5 \%$ level. In terms of area specific variables, most are significant at the $5 \%$ level but not HDD for zone $\mathrm{K}$, the square of CDD for zones $\mathrm{G}$ and $\mathrm{J}$, and the interaction term with CDD and the Sunday dummy variable for zones G and K.

In Table B.6 the parameter estimates of the $\operatorname{VAR}(1)$ model for the computed residuals are shown. The order of the VAR model was selected based on the $\mathrm{SBC}^{6}$. For the $\operatorname{VAR}(1)$ model, seven of the 16 variables are significant at the $5 \%$ level for lag 1 . It is interesting to note that the lagged residuals for zones G-I and J have significant cross effects with the other areas, while in contrast, the lagged residuals for $\mathrm{A}-\mathrm{F}$ and $\mathrm{K}$ do not.

\subsection{The model for electricity price}

The model for electricity price assumes that electricity quantity demanded and the price of natural gas at Henry Hub are important explanatory varibles. $^{7}$ After testing various fuctional forms, the quantity demanded for electricity, a distributed lag of the price of natural gas and seasonal and weekly patterns were selected as the exogenous variables. In Figure 4 the plot of the daily day-ahead electricity prices in zones $\mathrm{A}, \mathrm{G}, \mathrm{J}$ and $\mathrm{K}$ is shown. Price data has more complex features than those of temperature and quantity demanded. There are a lot of price spikes and other irregular patterns. However, the exogenous variables can explain many of these features. After the

\footnotetext{
${ }^{6}$ The SBCs are -29.8152 for $\operatorname{VAR}(1),-29.8078$ for $\operatorname{VAR}(2)$, and -29.8112 for $\operatorname{VAR}(3)$.

${ }^{7}$ Henry Hub natural gas is traded on NYMEX and it is an important factor determining the marginal cost of generation.
} 
A

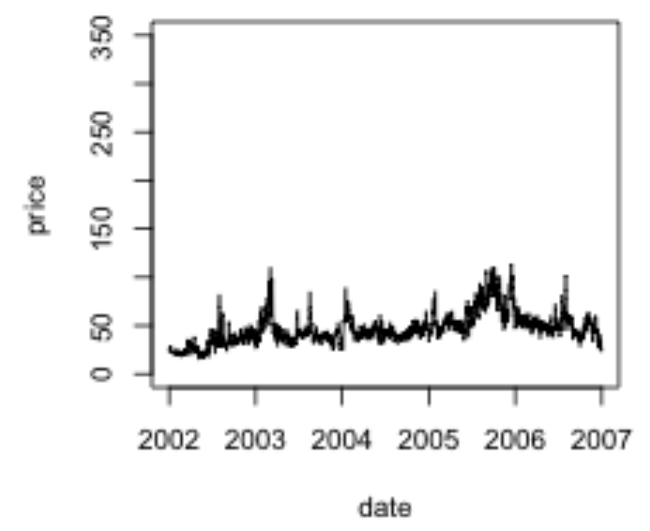

J

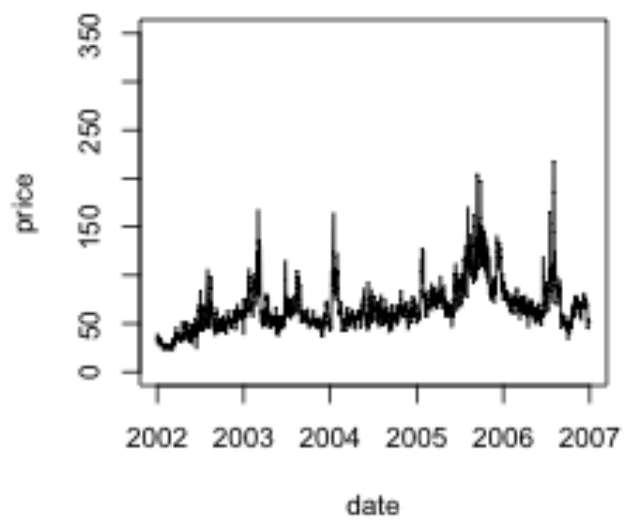

G

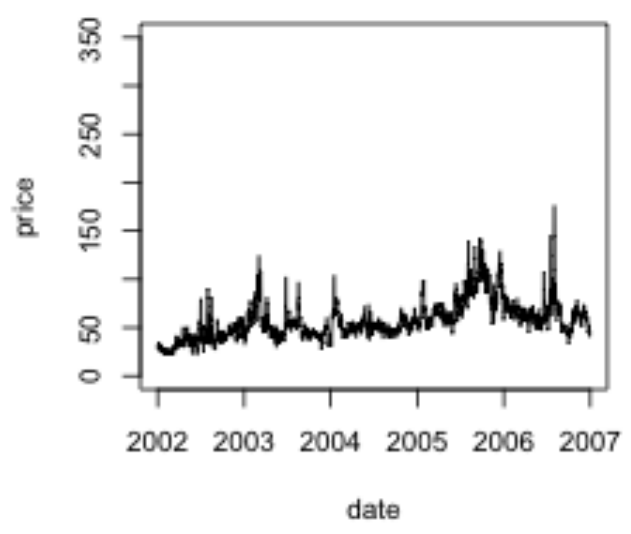

K

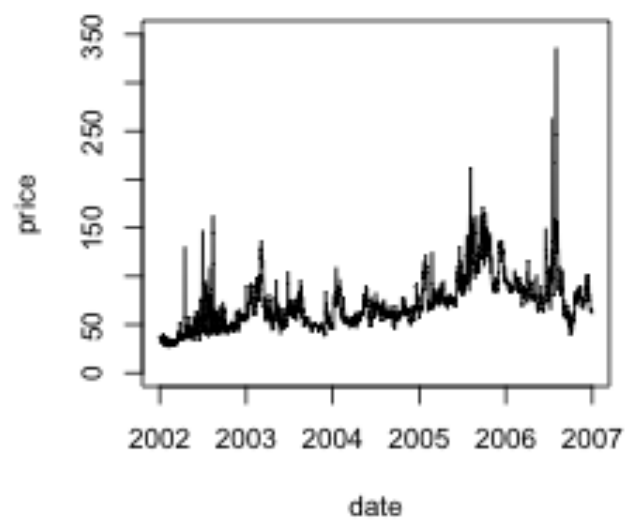

Figure 4: Price 
effects of the exogenous variables have been removed in the first step, the computed residuals are used to estimate a $\operatorname{VAR}(1)$ model using the $\mathrm{SBC}^{8}$. An equation for price can be expressed as follows:

Price Model.

$$
\begin{aligned}
& p_{i t}= \beta_{i 0}+\beta_{i 1} t_{t}+\beta_{i 2} \text { ch }_{t}+\beta_{i 3} s h_{t}+\beta_{i 4} c 1_{t}+\beta_{i 5} s 1_{t}+\beta_{i 6} c 2_{t}+\beta_{i 7} s 2_{t}+ \\
& \gamma_{i 1} \text { sunday }_{t}+\gamma_{i 2} \text { monday }_{t}+\gamma_{i 3} \text { tuesday }_{t}+ \\
& \gamma_{i 4} \text { wednesday }_{t}+\gamma_{i 5} \text { thursday }_{t}+\gamma_{i 6} \text { friday }_{t}+ \\
& \gamma_{i 7} \text { holiday }_{t}+ \\
& \eta_{i 1} w p 1_{t}+\eta_{i 2} w p 2_{t}+\kappa_{i 1} \text { log_demand }_{i t}+\kappa_{i 2} \text { log_demand }_{i t}^{2}+u_{i t} \\
& \Phi(L) \mathbf{u}_{t}=\epsilon_{t}
\end{aligned}
$$

$p_{i t}: \log$ of electricity price

$w p 1_{t}, w p 2_{t}$ : the weighted sums of price of natural gas

Table B.7 and B.8 show the parameter estimates of the price model in the four zones. $w p 1$ and $w p 2$ are the weighted sums of the log prices of natural gas, and a complete explanation is given in an Appendix. log_demand and sq_log_demand are the level and squared values of the log of demand. The other variables correspond to the same seasonal and weekly variables described for the model of quantity demanded. Table B.9 summarizes the estimated VAR(1) model for the residuals. Standard statistical tests show that the residuals from the $\operatorname{VAR}(1)$ model are white noise (uncorrelated through time $)^{9}$.

\subsection{Performance of the econometric model}

This section summarizes the fit of the estimated equations for temperature, electricity quantity demanded and electricity price. Since the three models are estimated in two stages and the first stage uses OLS, both the OLS R-squared and the overall pseudo R-squared are shown in Table 1. The pseudo R-squared $=100(1$ - Variance[white noise residuals]/Variance[dependent variable]) combines the fit associated with the exogenous variables in the OLS stage with the fit associated with the auto-correlations of the OLS residuals

\footnotetext{
${ }^{8}$ The SBCs are -19.786 for $\operatorname{VAR}(1),-19.7287$ for $\operatorname{VAR}(2),-19.6824$ for $\operatorname{VAR}(3)$

${ }^{9}$ The table of these results is not included in this paper.
} 
Table 1: R-squard Values for Models

\begin{tabular}{lcc}
\hline \hline & OLS R-squared & Pseudo R-squared \\
\hline Temperature & & \\
Buffalo & 0.8168 & 0.9097 \\
Stewart Field & 0.8270 & 0.9491 \\
LaGuardia Airport & 0.8317 & 0.9429 \\
Demand & & \\
A-F & 0.8980 & 0.9235 \\
G-I & 0.8761 & 0.9433 \\
J & 0.9409 & 0.9551 \\
K & 0.9129 & 0.9512 \\
Price & & \\
A & 0.8688 & 0.9365 \\
G & 0.8583 & 0.9389 \\
J & 0.8561 & 0.9402 \\
K & 0.8162 & 0.9152 \\
\hline \hline
\end{tabular}

in the VAR stage. In general, the fit of the model is satisfactory, and for the individual equations, the OLS R-squared are all over $80 \%$ and the pseudo R-squared are all over $90 \%$.

\section{Simulation Results}

The results of the price simulation for four zones (A, G, J and $\mathrm{K}$ ) are discussed in this section. The goal of the simulation is to calculate the expected payouts of 6-month TCCs before the auction to sell these contracts is held. Since the expected payout is thought by TCC buyers to be the value of the TCC, if the market clearing price of the TCC in the auction is lower than the average simulated value, this would provide evidence of under-pricing. Temperature is considered to be an exogenous variable that determines the daily quantity demanded. The daily quantity demanded and the price of natural gas are exogenous variables that determine the price of electricity. Using the models presented in Section 3, different realizations of daily temperature are simulated for the summer of 2006 (May to October) and these determine the corresponding realizations of quantity demanded, and the realizations of quantity demanded together with the forecasted price of natural gas determine the realizations of price. Since all four econometric 
Table 2: Parameter Estimates of the ARIMA(2,1,1) for Natural Gas Price

\begin{tabular}{rrr}
\hline \hline & \multicolumn{2}{c}{ Estimates } \\
\hline const & 0.0006 & $(0.61)$ \\
MA 1 & -0.2818 & $(-6.04)$ \\
AR 1 & 0.158 & $(3.70)$ \\
AR 2 & -0.4363 & $(-16.45)$ \\
\hline \hline
\end{tabular}

models were estimated using data that were available to analysts before the TCCs for the summer 2006 were purchased, the simulated prices can be used to determine a realistic range of forecasted payouts faced by someone purchasing a TCC for the coming summer. A deterministic benchmark forecast was computed followed by 10,000 simulations incorporating the uncertainty of the exogenous variables. The realizations of daily prices were used to compute the price differences for A-G, A-J, G-J and J-K and these differences were then used to determine the corresponding payout for a six-month strip. In other words, each realization of the daily prices for the six summer months produces one observation of the payout.

Temperature, quantity demanded and price realizations are simulated by the regression model with VAR residuals estimated in section 3.1, 3.2 and 3.3 using a random number generator to simulate a sample from a multivariate normal distribution for Buffalo, Stewart Field and LaGuardia Airport. In Figure 5 three graphs for one realization of the daily values of temperature, quantity demanded and price for the summer 2006 are shown. The first is the plot of daily temperatures in Buffalo, Stewart Field and LaGuardia Airport. The second is the plot of quantities demanded in zones A-F, zones G-I, zone J and zone $\mathrm{K}$. The third is the plot of prices for zones A, G, J and K. In Figure 6 one realization of the daily price differences between zone $\mathrm{J}$ and zone $\mathrm{G}$ derived from the prices in Figure 5 is shown. Figure 7 presents the frequency distribution of all of the simulated daily price differences for A-G, A-J, G-J, and J-K. In all four cases, the first zone listed is the injection region and the second is the withdrawal region. Although most price differences are positive, there are also a substantial number of negative differences, demonstrating the intrinsic uncertainty about the flow of daily payments for owners of these TCCs.

In Figure 8 the four frequency distributions of the payouts for the sixmonth strips derived from the daily price realizations for 10,000 simulated 

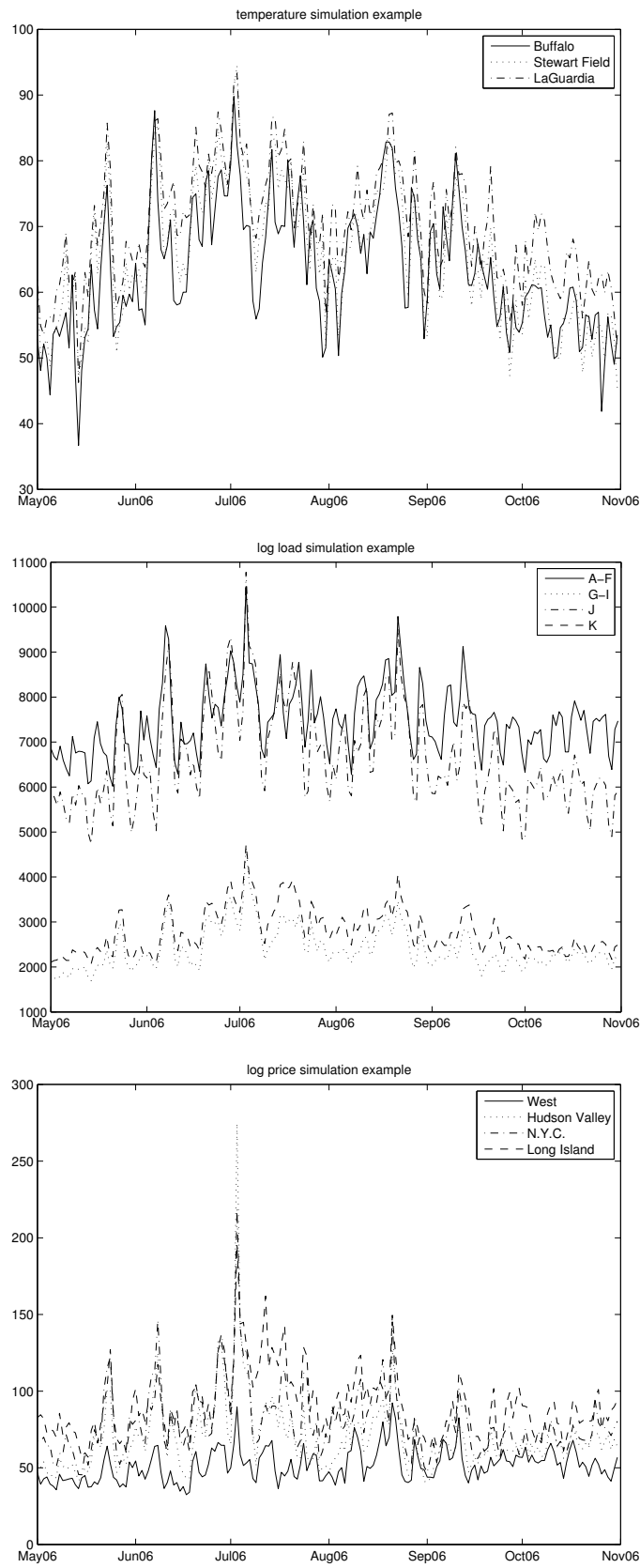

Figure 5: The Realization of Temperature, Quantity Demanded and Price of Electricity(One of 10,000 simulated values) 


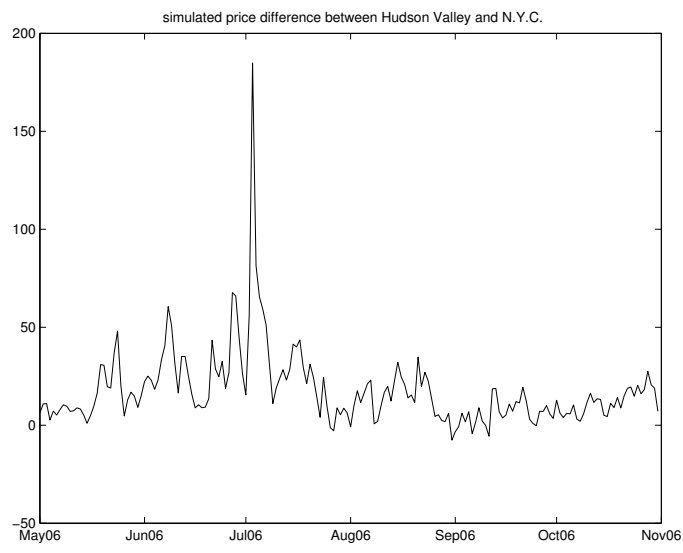

Figure 6: Simulated Hourly Price Difference between J and G(One of 10,000 simulated values)
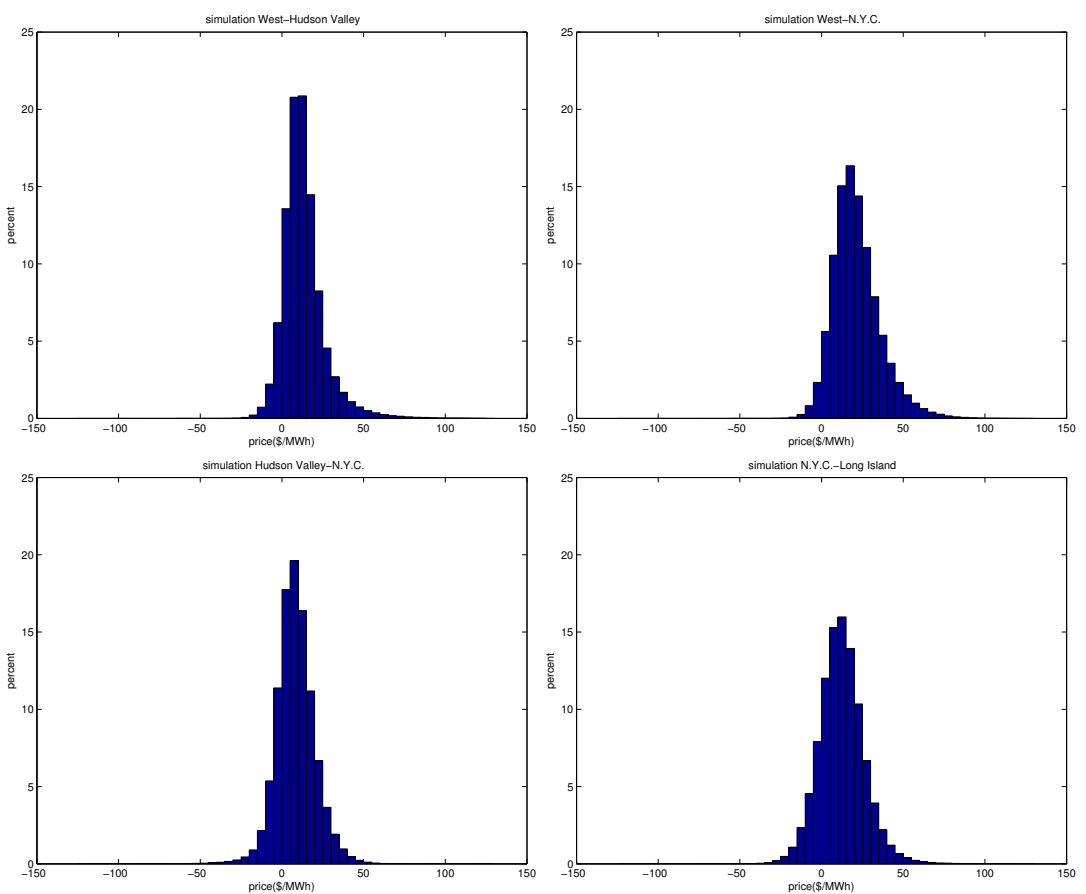

Figure 7: Histograms of Simulated Daily Price Differences, A-G, A-J, G-J and J-K 

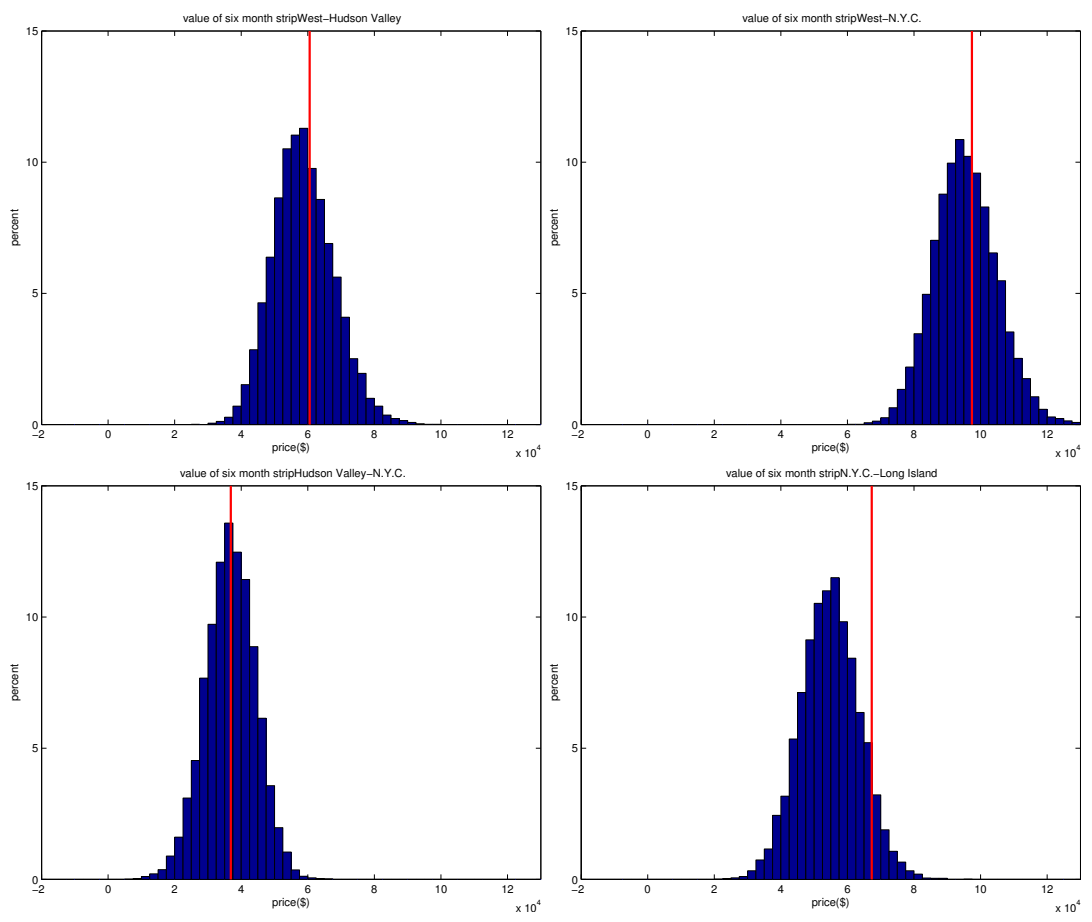

Figure 8: Simulated Payouts for a Six-Month Strip 
Table 3: Simulated Payouts of Six-Month Strips (unit:\$)

\begin{tabular}{rcrcc}
\hline \hline & A-G & A-J & G-J & J-K \\
\hline actual & 60544.53 & 97393.65 & 36849.12 & 67283.44 \\
& & & & \\
max & 98798.20 & 138993.95 & 66983.92 & 96652.53 \\
mean & 58721.02 & 95436.11 & 36715.08 & 54778.18 \\
median & 58251.94 & 95067.64 & 36806.68 & 54759.08 \\
min & 27224.19 & 60011.90 & 6815.03 & 21689.11 \\
& & & & \\
std.dev. & 9094.32 & 9476.55 & 7550.99 & 8885.09 \\
\hline \hline
\end{tabular}

summers (The actual payouts for the summer 2006 are expressed by vertical lines.) are shown. Although the distributions of the price differences are clearly skewed to the right, the distributions of the payouts are relatively symmetric. The main statistical characteristics of these distributions are summarized in Table 3. The actual payouts are higher than the means of the simulated payouts in all cases, but are all less than two standard deviations above the mean and the values for A-G, A-J and G-J are less than one standard deviation above the mean. Hence, we can conclude that the actual payouts for the six-month strips in the summer 2006 are consistent with the simulated distributions of payouts and are not extreme values. The unexpected blackout in Queens in September 2006 is a likely reason why the actual payout for J-K is larger than the simulated mean.

The main purpose of this paper is to evaluate the performance of the market for Transmission Congestion Contracts, in particular, to determine whether the prices paid for six-month TCCs show evidence of under-pricing. This is done by comparing the actual prices paid for the TCCs for the summer 2006 to the means of the simulated distributions adjusted for losses. Finding that the prices paid are substantially lower than the adjusted means would be evidence of under pricing. The most important TCC is the difference between the prices in zones $\mathrm{J}$ and $\mathrm{G}$ corresponding to the third graph in Figure 7. In the TCC auction, there were actually no direct six-month contracts sold for A-G, A-J or J-K and 279 contracts sold for G-J. Since the electricity delivery system on Long Island is operated by a public power authority, it is not surprising that there were no contracts for zone $\mathrm{K}$ but this is not true for A-G or A-J. A large amount of generation is transferred from upstate regions 
Table 4: Loss Adjusted Cost (unit:\$)

\begin{tabular}{rrrr}
\hline \hline & \multicolumn{1}{c}{ A-G } & \multicolumn{1}{c}{ A-J } & \multicolumn{1}{c}{ G-J } \\
\hline market clearing price & 9695.06 & 44761.95 & 35066.89 \\
cost of losses & 40754.81 & 44738.38 & 3983.57 \\
L.A.C.(=loss adjusted cost) & 50449.87 & 89500.33 & 39050.46 \\
& & & \\
mean simulated revenue & 58721.02 & 95436.11 & 36715.08 \\
mean simulated profit & 8271.15 & 5935.78 & -2335.38 \\
& & & \\
percentile of L.A.C. & $18.08 \%$ & $27.00 \%$ & $61.48 \%$ \\
\hline \hline
\end{tabular}

to New York City every day. As an alternative way to represent the volume of trading in the TCC market, zones were aggregated into upstate (zones A-F) and the lower Hudson Valley (zones G-I). The numbers of contracts from A-F to G-I and to J are 610 and 11, respectively, and the number from G-I to $\mathrm{J}$ is 1205. As expected, the volume for the Lower Hudson Valley to New York City is the largest.

In Table 4 the average market clearing prices for three six-month TCCs in the summer 2006 (A-G, A-J and G-J) are shown. Since there was no TCC trading for zone $\mathrm{K}$, no price is shown for J-K. In addition, the market price for A-G is represented by combining the TCC contracts for A-E and E-G, and the market price for A-J is the combination of A-E, E-G and G$J$. An observed difference in the nodal prices between two locations can be divided into the cost of congestion and the cost of losses. Since the actual payments made to the owners of a TCC do not include the cost of losses, the TCC prices in Table 4 are adjusted by adding the cost of losses to give the Loss Adjusted Cost (LAC $=$ average market clearing price + average cost of losses). The LAC is equivalent to the simulated payments presented in Figure 8. The mean simulated revenues in Table 4 are the same as the means shown in Table 3.

The results show that the LACs for A-G and A-J are lower than the simulated means and the LAC for G-J is higher than the simulated mean. In the last row of Table 4 the corresponding percentiles of the distribution of simulated payouts are shown for each LAC. The percentiles are 18.08\%, $27.00 \%$ and $61.48 \%$ for A-G, A-J and G-J, respectively. Even though the actual payouts shown in Table 3 are all higher than the simulated means, 
the adjusted market price for G-J, the most heavily traded TCC, is higher than the expected payout, and the adjusted market prices for A-G and A$\mathrm{J}$ are lower than the expected payouts. There is no consistent evidence of under-pricing for these three TCCs. The main source of under-pricing occurs for A-G. Since this underpricing is larger than the over-pricing for G-J, the corresponding contract for A-J is also under-priced. More importantly, the results illustrate why using a comparison of the actual ex-post payout to the market price of a TCC to judge the performance of a forward market can be misleading. A better evaluation should be based on a comparison of the market price to the ex-ante expected payout determined from evidence available before the market clears. The econometric procedures described in this paper illustrate how this can be done, and we believe that this is the first attempt to use this ex-ante approach in the literature.

\section{Summary and Conclusions}

In spite of the fact that the actual payouts for TCCs since 2002 were generally highly profitable ( $\mathrm{Ju}, 2009)$, no consistent evidence of the underpricing was found in this simulation analysis for the summer 2006 because the loss-adjusted market price is actually higher than the mean simulated payout for the important TCC for G-J. Hadsell and Shawky (2009) analyzed the TCC market in New York State using data for the period 2006-2008. They concluded that the efficiencies of markets for one-month and 12-month TCCs are questionable while the market for six-month TCCs is relatively efficient. The results of this paper generally support Hadsell's conclusion for six-month TCCs.

Our results are not consistent with Zhang's conclusion that the market prices paid for TCCs in New York State are under-priced. She develops a theoretical model that attributes under-pricing to monopsonic market power by sellers, risk-averse behavior by buyers and winner's curse in the auction's outcome. However, she bases her conclusion on a comparison of market prices to actual ex-post payouts rather than to the ex-ante expected payments.

The primary objective of his paper is to evaluate the efficiency of the TCC market in New York State by comparing the price paid for a TCC contract to the mean of the distribution of the likely payouts. The payouts are simulated using an econometric model estimated from data available before the TCC auction was held. By simulating 10,000 realizations of the payouts for a 6 month TCC (May to October 2006), the mean of the realized payouts can be 
compared to the actual payout of the TCC and the price paid for the TCC at the auction. As shown in Table 3 and Table 4, an important empirical conclusion from the analysis is that there is no consistent evidence of underpricing for three six-month TCCs in New York State in 2006 in spite of the high profitability from holding TCCs observed in most years (Ju, 2009). For two of the three TCCs evaluated (zones A-G and zones A-J), the market prices are consistent with under-pricing but the volumes of trading of these contracts are relatively small. The market price of the most highly traded TCC (zones G-J) is over-priced in the sense that the market price is higher than the mean of the simulated payouts. This is true even though the actual payouts are larger than the simulated means for all three TCCs. The main source of under-pricing comes from the TCC from Buffalo to the Hudson Valley (zones A-G), and this also affects the TCC from Buffalo to New York City (zones A-J) because it is simply a combination of the other two TCCs.

There are limitations in this study. First, only one actual realized value is used to compare to the simulation due to the lack of TCC auction cases in 2006 summer. Second, in the simulation parameters are assumed to be fixed because of computational complexity.

Although the analysis evaluates the efficiency of only a limited number of TCCs, the main purpose of the paper is to demonstrate the feasibility of using an econometric framework to do this type of evaluation. Extending the analysis by evaluating the TCCs for more years is an interesting objective for future research. In addition, the current results suggest that liquidity may be an important determining factor for the efficiency of a TCC market, and this is another interesting topic for future research.

\section{Acknowledgments}

The research was supported by the Consortium for Electric Reliability Technology Solutions (CERTS) program in the Office of Electricity Delivery and Energy Reliability, Transmission Reliability Program of the U.S. Department of Energy, and by the New York State Independent System Operator (NYISO) through the Power Systems Engineering Research Center (PSERC).

\section{References}

Cai, X., 2005. An evaluation of investment incentives for maintaining system adequacy in deregulated markets for electricity. Ph.D. thesis, Cornell 
University.

Fama, E. F., 1998. Market efficiency, long-term returns, and behavioral finance. Journal of Financial Economics 49, 283-306.

Hadsell, L., Shawky, H. A., 2009. Efficiency and profit in the nyiso transmission congestion contract market. The Electricity Journal 22, 47-57.

Hogan, W. W., 1992. Contract networks for electric power transmission. Journal of Regulatory Economics 4 (3), 211-242.

Hogan, W. W., 1997. A market power model with strategic interaction in electricity networks. Energy Journal 18 (4), 107-141.

Joskow, P. L., 2000. Transmission rights and market power on electric power networks. The RAND Journal of Economics 31 (3), 450-487.

Joskow, P. L., 2005. Transmission policy in the united states. Utilities Policy 13, 95-115.

Ju, J., 2009. Transmission networks and financial rights in the new york electricity market. Ph.D. thesis, Cornell University.

Mjelde, J. W., Bessler, D. A., 2009. Market integration among electricity markets and their major fuel source markets. Energy Economics 31, 482491.

NYISO, 2007. Transmission Congestion Contracts Manual. NYISO.

Park, H., Mjelde, J. W., Bessler, D. A., 2006. Price dynamics among u.s. electricity spot markets. Energy Economics 28, 81-101.

Park, H., Mjelde, J. W., Bessler, D. A., 2007. Time-varying threshold cointegration and the law of one price. Applied Economics 39, 1097-1105.

Zhang, N., 2009. Market performance and bidders' bidding behavior in the new york transmission congestion contract market. Energy Economics. 


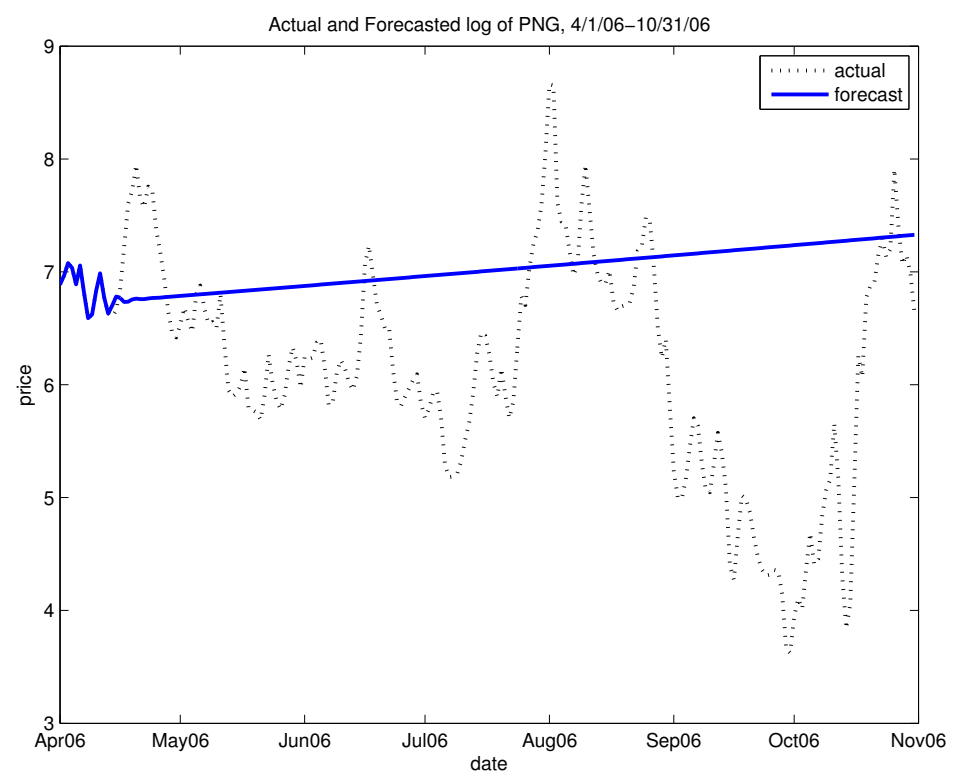

Figure A.9: Spot and Forecasted Prices of Natural Gas at Henry Hub, May-October, 2006

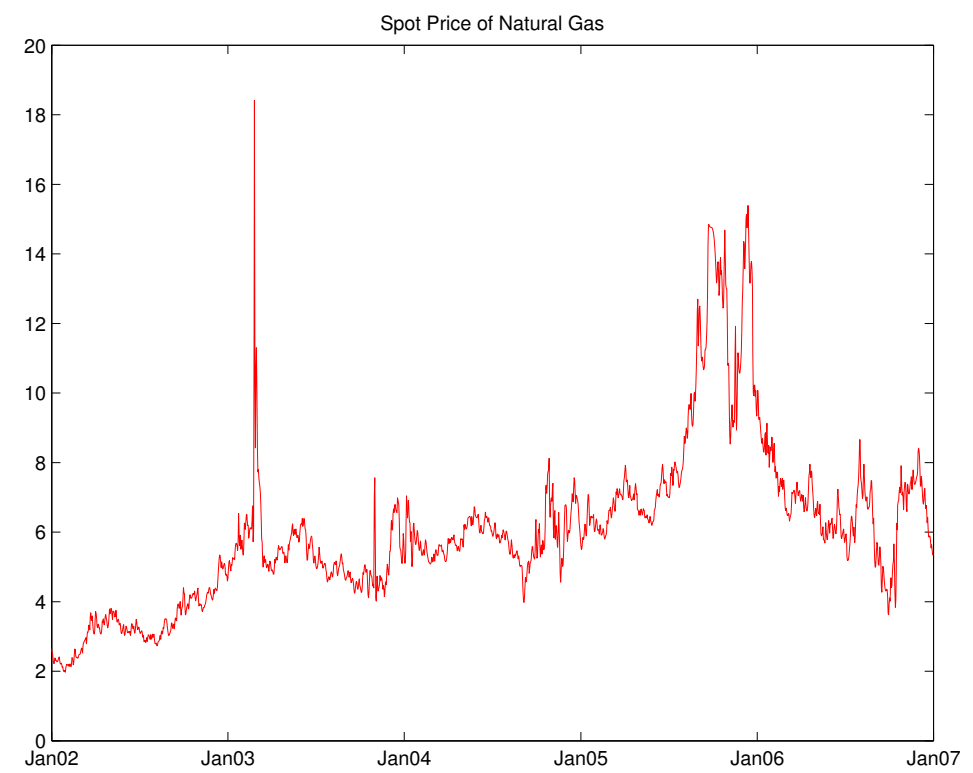

Figure A.10: Spot Price of Natural Gas at Henry Hub 


\section{Appendix A. Price of Natural Gas}

The price of natural gas is an important factor in determining electricity price in New York State because many of the generating units in the state are gas-fired plants, particularly in zones J and K. In Figure A.10 the daily spot prices for natural gas at Henry Hub from January 1st, 2002 to December 31st, 2006 (The missing values for Saturday and Sunday are computed by linear interpolation) are shown. It is reasonable to assume that daily electricity prices respond gradually to changes in natural gas prices through a distributed lag. In other words, the current price of electricity is affected by current and past values of the price of natural gas. Lagrange interpolation polynomials are used to reduce the number of coefficients that have to be estimated, and this assumes implicitly that the shape of the distributed lag is relatively smooth. Different lag lengths up to one month were considered, and the final model selected had a lag length of 12 days. Instead of estimating 12 coefficients for the 12 different prices, the relationship is specified as a quadratic polynomial which is defined by only three coefficients. In this model, 3 fixed base points (0,6 and 12) are chosen for the 3 polynomials, and the corresponding coefficients are estimates of the lag structure at 0,6 and 12 periods lagged, respectively. Since the estimates of the coefficient for lag 12 are close to zero, the third polynomial is dropped from the model to make the lag structure end at zero at lag 12 . The three polynomials for the lag structure can be calculated for $\mathrm{i}=0,1,2, \ldots, 12$ as follows:

$$
\begin{aligned}
& w_{1 i}=\frac{(i-6)(i-12)}{(0-6)(0-12)} \\
& w_{2 i}=\frac{(i-0)(i-12)}{(6-0)(6-12)} \\
& w_{3 i}=\frac{(i-0)(i-6)}{(12-0)(12-6)}
\end{aligned}
$$

Three weighted sums are computed as the product of the weight for each polynomial and the lagged value of the log price of natural gas as follows:

$$
w p_{k t}=\sum_{i=0}^{12} w_{k i} \log P N G_{t-i}
$$

Figure A.11 is the plot of the weighted sums of natural gas prices calculated by the Lagrange interpolation polynomials. 


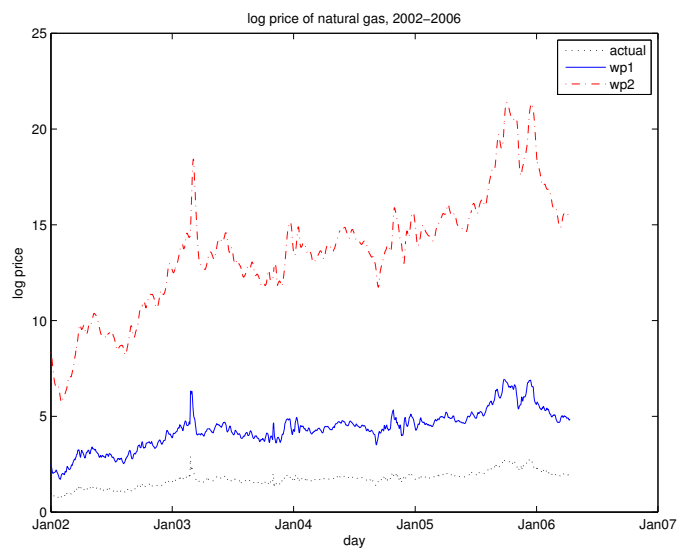

Figure A.11: Weighted Sums for the Log of Natural Gas Price

Table A.5: MINIC Table for Natural Gas Price

\begin{tabular}{lllllll}
\hline \hline & MA_0 & MA_1 & MA_2 & MA_3 & MA_4 & MA_5 \\
\hline AR 0 & -6.136 & -6.277 & -6.392 & -6.459 & -6.470 & -6.473 \\
AR 1 & -6.193 & -6.287 & -6.410 & -6.461 & -6.469 & -6.469 \\
AR 2 & -6.462 & -6.478 & -6.474 & -6.473 & -6.469 & -6.464 \\
AR 3 & -6.474 & -6.474 & -6.469 & -6.469 & -6.464 & -6.460 \\
AR 4 & -6.474 & -6.470 & -6.469 & -6.464 & -6.460 & -6.455 \\
AR 5 & -6.470 & -6.468 & -6.465 & -6.460 & -6.456 & -6.451 \\
\hline \hline
\end{tabular}

It is found by augmented Dickey-Fuller test that natural gas price has a unit root. Comparing information criteria, $\operatorname{ARIMA}(2,1,1)$ was chosen for the model. Table A.5 is minimum information criteria table for natural gas price.

The coefficients for the first two weighted sums $\left(w p_{1}, w p_{2}\right)$ are estimated in the model. $w p_{1}$ at lag 0 has the largest coefficient in all zones and the coefficients for $w p_{2}$ at lag 6 are approximately half as large as the coefficients for $w p_{1}$. In Table A.6 there are the estimated coefficients for the weighted sums in the four regions. Since the coefficients for J are the largest, this zone is the most sensitive to the price of natural gas. If the estimated coefficients are multiplied by the corresponding weights $w p_{1}$ and $w p_{2}$ for each lag, the sum of these products is the estimated coefficient of the distributed lag, and the sum of the distributed lag coefficients $\sum_{i=0}^{12}\left(\beta_{1} w_{1 i}+\beta_{2} w_{2 i}\right)$ is the estimated long-run price elasticity of natural gas. In Table A.7 there are the estimated 
Table A.6: Parameter Estimates of the Weighted Sum of Natural Gas Price

\begin{tabular}{|c|c|c|c|}
\hline & \multicolumn{2}{|c|}{$\mathrm{A}$} & G \\
\hline wp1 & 0.0863 & $(4.84)$ & $\begin{array}{ll}0.0809 & (4.81)\end{array}$ \\
\hline wp2 & 0.0682 & $(11.52)$ & (12.71) \\
\hline & & $\mathrm{J}$ & $\mathrm{K}$ \\
\hline wp1 & 0.0978 & $(5.52)$ & 0.0936 \\
\hline wp2 & 0.0721 & (12.27) & 0.0610 \\
\hline
\end{tabular}

Table A.7: Lag Coefficients for the Price of Natural Gas

\begin{tabular}{ccccc}
\hline \hline lag & $\mathrm{A}$ & $\mathrm{G}$ & $\mathrm{J}$ & $\mathrm{K}$ \\
\hline 0 & 0.0863 & 0.0809 & 0.0978 & 0.0936 \\
1 & 0.0867 & 0.0835 & 0.0967 & 0.0901 \\
2 & 0.0858 & 0.0845 & 0.0944 & 0.0859 \\
3 & 0.0835 & 0.0837 & 0.0908 & 0.0808 \\
4 & 0.0798 & 0.0812 & 0.0858 & 0.0750 \\
5 & 0.0747 & 0.0770 & 0.0796 & 0.0684 \\
6 & 0.0682 & 0.0711 & 0.0721 & 0.0610 \\
7 & 0.0603 & 0.0635 & 0.0633 & 0.0528 \\
8 & 0.0510 & 0.0542 & 0.0532 & 0.0438 \\
9 & 0.0404 & 0.0432 & 0.0419 & 0.0340 \\
10 & 0.0283 & 0.0305 & 0.0292 & 0.0235 \\
11 & 0.0148 & 0.0161 & 0.0152 & 0.0121 \\
12 & 0.0000 & 0.0000 & 0.0000 & 0.0000 \\
& & & & \\
sum & 0.7598 & 0.7696 & 0.8200 & 0.7210 \\
\hline \hline
\end{tabular}


Table B.1: Numbers of Nodes in New York State

\begin{tabular}{c|r|r|r|r|r|r|r|r|r}
\hline \hline year & 1999 & 2000 & 2001 & 2002 & 2003 & 2004 & 2005 & 2006 & 2007 \\
\hline \hline $\mathrm{A}$ & 23 & 24 & 28 & 30 & 30 & 31 & 31 & 32 & 32 \\
\hline $\mathrm{B}$ & 8 & 9 & 9 & 10 & 10 & 10 & 14 & 15 & 15 \\
\hline $\mathrm{C}$ & 34 & 35 & 45 & 46 & 47 & 47 & 47 & 46 & 46 \\
\hline $\mathrm{D}$ & 11 & 11 & 12 & 12 & 12 & 12 & 12 & 13 & 13 \\
\hline $\mathrm{E}$ & 23 & 24 & 25 & 25 & 26 & 31 & 32 & 32 & 32 \\
\hline $\mathrm{F}$ & 23 & 27 & 35 & 38 & 39 & 40 & 44 & 45 & 45 \\
\hline $\mathrm{G}$ & 26 & 27 & 28 & 28 & 28 & 28 & 29 & 29 & 29 \\
\hline $\mathrm{H}$ & 6 & 7 & 9 & 9 & 9 & 9 & 9 & 9 & 9 \\
\hline $\mathrm{I}$ & 1 & 1 & 2 & 2 & 2 & 2 & 2 & 2 & 2 \\
\hline $\mathrm{J}$ & 108 & 109 & 123 & 123 & 126 & 126 & 132 & 133 & 133 \\
\hline $\mathrm{K}$ & 52 & 52 & 55 & 67 & 70 & 72 & 74 & 74 & 74 \\
\hline \hline Subtotal & 315 & 326 & 371 & 390 & 399 & 408 & 426 & 430 & 430 \\
\hline \hline $\mathrm{M}$ & 1 & 1 & 1 & 1 & 1 & 1 & 1 & 1 & 1 \\
\hline $\mathrm{N}$ & 1 & 1 & 1 & 1 & 1 & 1 & 2 & 2 & 2 \\
\hline $\mathrm{O}$ & 1 & 1 & 1 & 1 & 1 & 1 & 1 & 1 & 1 \\
\hline $\mathrm{P}$ & 1 & 1 & 1 & 1 & 1 & 1 & 1 & 1 & 1 \\
\hline $\mathrm{U}$ & 40 & 39 & 33 & 34 & 25 & 25 & 25 & 6 & 18 \\
\hline \hline Total & 359 & 369 & 408 & 428 & 428 & 437 & 456 & 441 & 453 \\
\hline \hline
\end{tabular}

coefficients of the complete distributed lag for $\mathrm{i}=0,1, \ldots, 12$ for the four zones and the estimated long-run elasticities. The long-run elasticity is 0.82 in $\mathrm{J}$ and between 0.7 and 0.8 in the other three zones.

\section{Appendix B. Tables}


Table B.2: Parameter Estimates of Temperature Deseasonalization

\begin{tabular}{rrrrrrr}
\hline \hline & \multicolumn{2}{c}{ Buffalo } & \multicolumn{2}{c}{ Stewart Field } & \multicolumn{2}{c}{ LaGuardia } \\
\hline const & 48.6116 & $(237.58)$ & 50.5901 & $(259.37)$ & 55.4617 & $(303.58)$ \\
& & & & & & \\
ch & 1.4767 & $(5.19)$ & 1.8801 & $(6.93)$ & 1.9634 & $(7.72)$ \\
c1 & -21.6823 & $(-74.81)$ & -22.0650 & $(-79.86)$ & -20.2500 & $(-78.25)$ \\
s1 & -9.9684 & $(-34.61)$ & -8.3615 & $(-30.46)$ & -9.6442 & $(-37.51)$ \\
\hline \hline
\end{tabular}

Table B.3: Parameter Estimates of $\operatorname{VAR}(2)$ for Temperature

\begin{tabular}{rrrrrrr}
\hline \hline Variables & \multicolumn{2}{c}{ Buffalo } & \multicolumn{2}{c}{ Stewart Field } & \multicolumn{2}{c}{ LaGuardia } \\
\hline const & 0.0110 & $(0.08)$ & 0.0069 & $(0.07)$ & 0.0069 & $(0.06)$ \\
lag \#1 & & & & & & \\
Buffalo & 0.8961 & $(30.15)$ & 0.7446 & $(34.02)$ & 0.6380 & $(28.98)$ \\
Stewart Field & -0.2895 & $(-4.10)$ & 0.1607 & $(3.09)$ & -0.1848 & $(-3.53)$ \\
LaGuardia & 0.1393 & $(2.06)$ & 0.1550 & $(3.12)$ & 0.5614 & $(11.22)$ \\
& & & & & & \\
lag \#2 & & & & & & \\
Buffalo & -0.2675 & $(-7.17)$ & -0.3464 & $(-12.60)$ & -0.3217 & $(-11.64)$ \\
Stewart Field & 0.2497 & $(3.75)$ & 0.2204 & $(4.49)$ & 0.1558 & $(3.16)$ \\
LaGuardia & -0.0292 & $(-0.43)$ & -0.1151 & $(-2.31)$ & -0.0816 & $(-1.63)$ \\
\hline \hline
\end{tabular}


Table B.4: Parameter Estimates for Electricity Quantity Demanded 1

\begin{tabular}{rrrrr}
\hline \hline & \multicolumn{2}{c}{ A-F } & \multicolumn{2}{c}{ G-I } \\
\hline const & 8.8251 & $(2173.97)$ & 7.4905 & $(1215.48)$ \\
& & & & \\
$\mathrm{t}$ & 0.0000 & $(-9.33)$ & 0.0001 & $(19.43)$ \\
$\mathrm{ch}$ & -0.0081 & $(-7.23)$ & -0.0185 & $(-10.78)$ \\
$\mathrm{sh}$ & 0.0011 & $(0.89)$ & 0.0197 & $(10.88)$ \\
$\mathrm{c} 1$ & 0.0124 & $(4.36)$ & -0.0018 & $(-0.38)$ \\
$\mathrm{s} 1$ & -0.0180 & $(-10.79)$ & -0.0345 & $(-14.40)$ \\
$\mathrm{c} 2$ & 0.0200 & $(16.04)$ & 0.0411 & $(20.65)$ \\
$\mathrm{s} 2$ & 0.0279 & $(20.31)$ & 0.0368 & $(17.86)$ \\
& & & & \\
sunday & -0.0297 & $(-9.29)$ & -0.0268 & $(-5.43)$ \\
monday & 0.0964 & $(29.92)$ & 0.0706 & $(14.00)$ \\
tuesday & 0.1014 & $(31.44)$ & 0.0755 & $(15.13)$ \\
wednesday & 0.1011 & $(31.49)$ & 0.0758 & $(15.22)$ \\
thursday & 0.1011 & $(31.58)$ & 0.0771 & $(15.47)$ \\
friday & 0.0801 & $(25.07)$ & 0.0697 & $(14.01)$ \\
holiday & -0.1124 & $(-19.85)$ & -0.0806 & $(-9.31)$ \\
& & & & \\
hdd_buf & -0.0014 & $(-4.93)$ & -0.0019 & $(-4.32)$ \\
hdd_buf_sq & 0.0000 & $(11.78)$ & 0.0001 & $(10.09)$ \\
cdd_buf & 0.0073 & $(6.52)$ & 0.0127 & $(8.30)$ \\
cdd_buf_sq & -0.0001 & $(-1.84)$ & 0.0000 & $(0.17)$ \\
hdd_buf1 & 0.0020 & $(13.63)$ & 0.0012 & $(5.26)$ \\
cdd_buf1 & 0.0070 & $(14.99)$ & 0.0079 & $(11.99)$ \\
& & & & \\
cbuf_sun & 0.0013 & $(1.37)$ & 0.0013 & $(1.07)$ \\
cbuf_mon & 0.0025 & $(2.74)$ & 0.0018 & $(1.54)$ \\
cbuf_tue & 0.0033 & $(3.70)$ & 0.0021 & $(1.81)$ \\
cbuf_wed & 0.0035 & $(3.74)$ & 0.0021 & $(1.81)$ \\
cbuf_thu & 0.0031 & $(3.46)$ & 0.0019 & $(1.61)$ \\
cbuf_fri & 0.0031 & $(3.29)$ & 0.0023 & $(1.90)$ \\
\hline \hline
\end{tabular}


Table B.5: Parameter Estimates for Electricity Quantity Demanded 2

\begin{tabular}{rrrrr}
\hline \hline & \multicolumn{3}{c}{$\mathrm{J}$} & \multicolumn{2}{c}{$\mathrm{K}$} \\
\hline const & 8.4847 & $(1850.87)$ & 7.6348 & $(1343.46)$ \\
$\mathrm{t}$ & 0.0000 & $(22.39)$ & 0.0000 & $(14.42)$ \\
$\mathrm{ch}$ & -0.0067 & $(-5.22)$ & -0.0071 & $(-4.41)$ \\
sh & 0.0004 & $(0.27)$ & -0.0083 & $(-4.96)$ \\
$\mathrm{c} 1$ & -0.0272 & $(-7.86)$ & -0.0510 & $(-11.90)$ \\
s1 & -0.0228 & $(-11.10)$ & -0.0532 & $(-20.88)$ \\
c2 & 0.0221 & $(15.14)$ & 0.0322 & $(17.79)$ \\
s2 & 0.0242 & $(14.21)$ & 0.0355 & $(16.84)$ \\
& & & & \\
sunday & -0.0351 & $(-9.14)$ & -0.0340 & $(-7.16)$ \\
monday & 0.1181 & $(30.41)$ & 0.0662 & $(13.74)$ \\
tuesday & 0.1218 & $(31.43)$ & 0.0664 & $(13.81)$ \\
wednesday & 0.1227 & $(31.72)$ & 0.0678 & $(14.13)$ \\
thursday & 0.1230 & $(31.86)$ & 0.0674 & $(14.08)$ \\
friday & 0.1126 & $(29.23)$ & 0.0620 & $(12.98)$ \\
holiday & -0.1032 & $(-15.93)$ & -0.0576 & $(-7.17)$ \\
& & & & \\
hdd_buf & -0.0015 & $(-4.04)$ & 0.0010 & $(2.26)$ \\
hdd_buf_sq & 0.0001 & $(8.56)$ & 0.0000 & $(3.95)$ \\
cdd_buf & 0.0082 & $(9.27)$ & 0.0097 & $(8.77)$ \\
cdd_buf_sq & 0.0000 & $(-0.25)$ & 0.0001 & $(2.24)$ \\
hdd_buf1 & 0.0010 & $(5.24)$ & 0.0019 & $(8.02)$ \\
cdd_buf1 & 0.0077 & $(19.37)$ & 0.0066 & $(13.48)$ \\
& & & & \\
cbuf_sun & 0.0013 & $(2.07)$ & 0.0010 & $(1.33)$ \\
cbuf_mon & 0.0025 & $(4.17)$ & 0.0008 & $(1.01)$ \\
cbuf_tue & 0.0026 & $(4.34)$ & 0.0010 & $(1.29)$ \\
cbuf_wed & 0.0024 & $(3.95)$ & 0.0007 & $(0.88)$ \\
cbuf_thu & 0.0025 & $(4.07)$ & 0.0010 & $(1.38)$ \\
cbuf_fri & 0.0029 & $(4.64)$ & 0.0016 & $(2.10)$ \\
\hline \hline & & & & \\
\hline \hline
\end{tabular}


Table B.6: Parameter Estimates for a VAR(1) for Electricity Quantity Demanded

\begin{tabular}{rrrrr}
\hline \hline \multicolumn{2}{c}{ A-F } & \multicolumn{2}{c}{ G-I } \\
\hline const & 0.0000 & $(0.02)$ & -0.0001 & $(-0.12)$ \\
& & & & \\
A-F & 0.4964 & $(18.09)$ & -0.0053 & $(-0.16)$ \\
G-I & 0.0339 & $(1.86)$ & 0.8029 & $(37.09)$ \\
J & -0.0271 & $(-0.91)$ & -0.1450 & $(-4.07)$ \\
K & -0.0107 & $(-0.51)$ & -0.0368 & $(-1.47)$ \\
\hline \hline \multicolumn{4}{c}{$\mathrm{J}$} & \multicolumn{2}{c}{$\mathrm{K}$} \\
\hline const & 0.0000 & $(0.00)$ & 0.0000 & $(0.03)$ \\
& & & & \\
A-F & -0.0269 & $(-0.85)$ & -0.0339 & $(-1.01)$ \\
G-I & 0.0295 & $(1.41)$ & -0.0290 & $(-1.30)$ \\
J & 0.4496 & $(13.11)$ & -0.1336 & $(-3.66)$ \\
K & 0.0366 & $(1.52)$ & 0.7503 & $(29.20)$ \\
\hline \hline
\end{tabular}


Table B.7: Parameter Estimates - Price of Electricity 1

\begin{tabular}{rrrrr}
\hline \hline & \multicolumn{3}{c}{$\mathrm{A}$} & \multicolumn{2}{c}{$\mathrm{G}$} \\
\hline const & -9.5730 & $(-0.41)$ & 51.3483 & $(5.74)$ \\
$\mathrm{t}$ & 0.0000 & $(1.36)$ & -0.0001 & $(-6.23)$ \\
$\mathrm{ch}$ & -0.0193 & $(-3.88)$ & -0.0183 & $(-3.83)$ \\
$\mathrm{sh}$ & -0.0207 & $(-3.63)$ & -0.0277 & $(-4.99)$ \\
$\mathrm{c} 1$ & -0.0318 & $(-6.05)$ & 0.0387 & $(7.26)$ \\
$\mathrm{s} 1$ & -0.0226 & $(-4.51)$ & 0.0362 & $(6.93)$ \\
$\mathrm{c} 2$ & -0.0928 & $(-15.77)$ & -0.0909 & $(-14.65)$ \\
$\mathrm{s} 2$ & -0.0147 & $(-2.24)$ & -0.0155 & $(-2.46)$ \\
& & & & \\
sunday & 0.0151 & $(1.15)$ & -0.0224 & $(-1.81)$ \\
monday & -0.0585 & $(-3.90)$ & 0.0285 & $(2.19)$ \\
tuesday & -0.0849 & $(-5.62)$ & 0.0070 & $(0.53)$ \\
wednesday & -0.1018 & $(-6.76)$ & -0.0046 & $(-0.36)$ \\
thursday & -0.1109 & $(-7.38)$ & -0.0046 & $(-0.35)$ \\
friday & -0.0840 & $(-5.84)$ & -0.0108 & $(-0.84)$ \\
holiday & 0.0253 & $(0.98)$ & -0.0715 & $(-3.00)$ \\
& & & & \\
png1 & 0.0863 & $(4.84)$ & 0.0809 & $(4.81)$ \\
png2 & 0.0682 & $(11.52)$ & 0.0711 & $(12.71)$ \\
& & & & \\
log_LA & 0.7658 & $(0.15)$ & -13.8321 & $(-5.96)$ \\
sq_log_LA & 0.0657 & $(0.23)$ & 0.9771 & $(6.50)$ \\
\hline \hline
\end{tabular}


Table B.8: Parameter Estimates - Price of Electricity 2

\begin{tabular}{rrrrr}
\hline \hline & \multicolumn{2}{c}{$\mathrm{J}$} & \multicolumn{2}{c}{$\mathrm{K}$} \\
\hline const & 23.3402 & $(2.09)$ & 76.6004 & $(7.81)$ \\
$\mathrm{t}$ & -0.0002 & $(-10.43)$ & 0.0000 & $(1.62)$ \\
$\mathrm{ch}$ & -0.0401 & $(-8.15)$ & -0.0443 & $(-7.88)$ \\
$\mathrm{sh}$ & -0.0187 & $(-3.26)$ & 0.0087 & $(1.34)$ \\
$\mathrm{c} 1$ & 0.1097 & $(14.68)$ & 0.0345 & $(4.65)$ \\
$\mathrm{s} 1$ & 0.0274 & $(4.55)$ & 0.0473 & $(6.84)$ \\
$\mathrm{c} 2$ & -0.0532 & $(-8.80)$ & -0.0186 & $(-2.61)$ \\
$\mathrm{s} 2$ & -0.0148 & $(-2.11)$ & 0.0221 & $(2.72)$ \\
& & & & \\
sunday & -0.0141 & $(-1.06)$ & -0.0228 & $(-1.54)$ \\
monday & -0.0564 & $(-3.65)$ & 0.0338 & $(2.20)$ \\
tuesday & -0.0882 & $(-5.66)$ & 0.0319 & $(2.08)$ \\
wednesday & -0.0951 & $(-6.09)$ & 0.0240 & $(1.56)$ \\
thursday & -0.0982 & $(-6.30)$ & 0.0203 & $(1.33)$ \\
friday & -0.0832 & $(-5.47)$ & 0.0110 & $(0.72)$ \\
holiday & -0.0567 & $(-2.20)$ & -0.0755 & $(-2.67)$ \\
& & & & \\
png1 & 0.0978 & $(5.52)$ & 0.0936 & $(4.66)$ \\
png2 & 0.0721 & $(12.27)$ & 0.0610 & $(9.19)$ \\
& & & & \\
log_LA & -6.1748 & $(-2.43)$ & -19.5582 & $(-7.90)$ \\
sq_log_LA & 0.4405 & $(3.05)$ & 1.2956 & $(8.29)$ \\
\hline \hline
\end{tabular}


Table B.9: Parameter Estimates of VAR(1) for Price of Electricity

\begin{tabular}{rrrrr}
\hline \hline \multicolumn{3}{c}{$\mathrm{A}$} & \multicolumn{2}{c}{$\mathrm{G}$} \\
\hline const & 0.0000 & $(0.01)$ & 0.0001 & $(0.06)$ \\
& & & & \\
$\mathrm{A}$ & 0.7128 & $(32.06)$ & 0.0117 & $(0.57)$ \\
$\mathrm{G}$ & -0.0121 & $(-0.45)$ & 0.6634 & $(26.17)$ \\
$\mathrm{J}$ & 0.0395 & $(1.75)$ & 0.0624 & $(2.97)$ \\
$\mathrm{K}$ & 0.0351 & $(1.86)$ & 0.0571 & $(3.25)$ \\
\hline \hline \multicolumn{4}{c}{$\mathrm{J}$} & \multicolumn{3}{c}{$\mathrm{K}$} \\
\hline const & 0.0001 & $(0.05)$ & 0.0000 & $(0.00)$ \\
& \multicolumn{3}{c}{} \\
$\mathrm{A}$ & 0.0030 & $(0.14)$ & 0.0274 & $(1.08)$ \\
$\mathrm{G}$ & 0.1579 & $(6.05)$ & 0.0997 & $(3.20)$ \\
$\mathrm{J}$ & 0.6384 & $(29.55)$ & 0.0464 & $(1.80)$ \\
$\mathrm{K}$ & 0.0354 & $(1.95)$ & 0.6490 & $(30.03)$ \\
\hline \hline
\end{tabular}

